\title{
Padrões espaciais de serviços avançados de apoio às empresas na rede urbana brasileira
}

\author{
Marcelo Paiva da Motta \\ Ronaldo Cerqueira Carvalho
}

O presente capítulo visa caracterizar a presença das firmas de serviços avançados de apoio às empresas na rede urbana em escala nacional, tanto vistas por sua localização absoluta, quanto pelas redes de sedes e filiais em que operam. É preciso sempre ter em conta que este tipo de firma é aquele com o propósito de garantir a aceleração da circulação e acumulação de capital, sendo, portanto, centrais para se entender a geografia do Brasil contemporâneo.

Promotoras ativas do city-ness, isto é, o conjunto de relações que as atividades de uma cidade realizam com seus pares em longa distância (TAYLOR; HOYLER; VERBRUGGEN, 2010), as firmas de serviços avançados funcionam como um "termômetro" do grau de sofisticação das economias locais, ligando-se às empresas mais dinâmicas, sendo em si atividades inovadoras e de alto valor agregado. Nesse contexto, o sistema de cidades não é concebido simplesmente como hierarquias baseadas em hinterlândias estanques, mas como conjunto de nós críticos para o funcionamento da economia de mercado.

\section{Breves observações conceituais}

Toda rede urbana possui uma natureza dupla, com duas dimensões invariavelmente presentes em sua estrutura. A primeira está associada ao papel econômico das cidades de fornecer bens e serviços para a população dispersa no território e nos demais centros urbanos. Nessa dimensão, o sistema urbano forma áreas de influência baseadas na contiguidade, no espaço contínuo - a partir do alcance que as funções urbanas possuem - e no deslocamento 
da população que as adquire. Via de regra, quanto maior o tamanho demográfico de uma cidade, mais ela acumula funções urbanas e maior é sua área de influência ou hinterlândia, formando um encadeamento de subordinações entre os centros urbanos. Essa dimensão possui um longo histórico de estudos (BROWN, 1994) e é bem caracterizada pela teoria clássica das localidades centrais de Christaller (1966).

Contudo, nos escalões superiores da hierarquia urbana, os processos econômicos baseados na fricção da distância - quanto mais os indivíduos têm que se deslocar para adquirir um bem ou serviço, maior será seu custo e raridade - e na contiguidade perdem importância em face dos relacionamentos à longa distância que as atividades lá localizadas realizam. Nesse sentido, as redes urbanas podem ser descritas como estruturas espaciais formadas tanto por ligações locais (CHRISTALLER, 1966), quanto por não locais, como preconizado pela teoria dos fluxos centrais de Taylor, Hoyler e Verbruggen (2010).

De acordo com a teoria dos fluxos centrais, as metrópoles e as grandes cidades não se tornaram o que são apenas a partir das relações locais do centro urbano com sua área de influência, pois estas últimas são insuficientes para explicar seu funcionamento.

Com efeito, enquanto o modelo das localidades centrais é essencialmente estático e não inclui mecanismos de expansão da atividade econômica e o surgimento de "novo trabalho" - atividades inovadoras que criam uma divisão do trabalho mais complexa -, o ambiente econômico das cidades, bem como sua função, só são explicáveis a partir de um modelo transacional mais amplo. Tal modelo leva em conta as interações entre os diferentes centros urbanos operacionalizados pelas atividades neles localizadas, através de distâncias e em escalas as mais distintas.

Nesse sentido, as firmas de serviços avançados de apoio às empresas constituem um dos grandes agentes das ligações a distância, uma vez que para atender seus mercados diversas empresas de variados ramos e escalas de produção - necessitam buscar recursos localizados em pontos diversos do espaço.

As redes de escritórios, sedes e filiais que realizam as conexões dessas firmas são construídas, majoritariamente, por meios eletrônicos, entre as cidades. Concretamente, são empresas de advocacia, consultoria legal, financiamento, propaganda e marketing, instituições bancárias, desenvolvimento tecnológico etc. Embora essas firmas pertençam a diferentes ramos de negócio e cada qual tenha sua estratégia particular, ao analisar os padrões espaciais agregados de suas atuações, é possível definir os grandes centros emissores de ordens em que se localizam as sedes, os polos de atração de escritórios, filiais e os padrões espaciais de interação entre as cidades, que não se comportam necessariamente de maneira hierárquica, como na busca por bens e serviços clássica.

Nas ligações entre cidades estabelecidas por essas empresas, caracterizadas como facilitadoras, portadoras e mesmo geradoras de inovação, intensivas em informação e conhecimento em seus processos de trabalho (HERTOG, 2000), são importantes também as conexões "transversais", complementares, entre cidades cuja hierarquia clássica é semelhante. 
As duas vertentes dessa natureza dual do fato urbano estão presentes em maior ou menor grau em todos os centros urbanos, embora uma delas seja dominante, governando os processos de urbanização. Nas cidades de maior porte, sobretudo nas metrópoles ${ }^{1}$, há a hegemonia dos processos baseados em redes, onde sua economia se explica mais pelo amálgama de relacionamentos a distância suscitados pelas aglomerações de firmas ali presentes, ao que Taylor (2012) denomina city-ness. Isto não quer dizer que a formação de hinterlândias esteja ausente, apenas que, na essência dessas cidades, a tradicional busca por bens e serviços adquire uma importância secundária.

As cidades menores, por sua vez, tendem a se organizarem antes pelo town-ness - a capacidade de polarização de suas funções urbanas - do que pelas relações de longa distância que, igualmente, não estarão totalmente ausentes, como é o caso das pequenas cidades da Região Centro-Oeste do Brasil cujo agronegócio é profundamente articulado aos mercados globais.

\section{Notas metodológicas}

Este estudo é um desdobramento de análise da publicação Gestão do território 2014, divulgada pelo IBGE no âmbito do projeto Redes e Fluxos do Território, onde foi destacada a diversidade na oferta de serviços avançados de apoio às empresas² (GESTÃO..., 2014, p. 98-102).

O presente capítulo procura enfatizar o quantitativo de empresas envolvidas neste segmento de mercado, seu padrão de localização e seu posicionamento em diversos recortes espaciais.

Como, dentre esses objetivos, buscou-se também avaliar espacialmente a distribuição de serviços avançados de apoio às empresas nas cidades, os dados foram agregados por Área de Concentração de População (ACP) $)^{3}$, elaboradas de acordo com a metodologia de Castello Branco (2006), de forma a se trabalhar o mais próximo possível com as reais unidades urbanas, descontando os recortes político-administrativos. Os municípios, entretanto, também foram considerados como forma de se obter uma análise mais apurada do padrão de localização das empresas que são objeto deste estudo, bem como para os casos onde as Áreas de Concentração de População não se apliquem.

A fonte de dados primária, cujo ano de referência é 2011, foi obtida do Cadastro Central de Empresas - CEMPRE, do IBGE, considerando somente as entidades empresariais (ESTATÍSTICAS..., 2013). Desta base de dados não foram incluídos os registros de microempreendedores individuais, empresas da administração pública, entidades empresariais sem fins

\footnotetext{
1 As metrópoles são aqui entendidas como os centros urbanos de grande porte que se encontram no topo da hierarquia urbana nacional, cuja unidade seja constituída de diversas entidades municipais, com complexidade interna e grande população.

2 Os termos "empresa", "firma" e "companhia" são tratados como sinônimos no presente estudo.

3 As Áreas de Concentração de População (ACP) são definidas como grandes manchas urbanas de ocupação contínua, identificadas por características ligadas à densidade populacional, urbanização e coesão interna de sua área. A Área de Concentração de População de São Paulo é considerada o maior conjunto urbano do País, alocada no primeiro nível da gestão territorial (REGIÕES..., 2008).
} 
lucrativos, pessoas físicas com Cadastro Nacional de Pessoas Jurídicas - CNPJ, organizações internacionais e outras instituições extraterritoriais. Selecionou-se, do CEMPRE, um conjunto de empresas classificadas como possuindo uma natureza administrativa, contábil, jurídica, financeira e de publicidade ${ }^{4}$ (GESTÃO..., 2014), em consonância com as categorizações de Sassen (1998) e Taylor (2001), de forma a se manter o mais próximo possível do tema de serviços avançados.

Para a identificação das cidades onde ocorrem aglomerações de firmas de serviços avançados, foi utilizada a metodologia desenvolvida por Crocco e outros (2006), que se baseia na geração do Índice de Concentração normalizado (ICn).

O ICn é constituído pela soma ponderada de três outros indicadores, sendo o primeiro o quociente locacional (QL), técnica de uso clássico na identificação de aglomerações produtivas. Este índice compara o peso da atividade em questão em cada município, no caso o número de empresas de serviços avançados, com a média nacional, de acordo com a fórmula:

$$
Q L=\frac{\frac{E_{j}^{s a}}{E_{j}}}{\frac{E_{B R}^{s a}}{E_{B R}}}
$$

onde:

$E_{j}^{\text {sa }}{ }_{j}$ corresponde ao número de empresas de serviços avançados no município ou ACP $j$;

$E_{j}$ é o número total de empresas no município ou ACP $j$.

$E_{B R}^{s a}$ significa o total de empresas de serviços avançados no Brasil; e

$E_{B R}$ corresponde ao total de empresas no País.

Esse índice possui a vantagem de ter como parâmetro a média nacional, estando as cidades acima de 1 como possíveis candidatos a abrigarem um cluster de empresas. Também tem a desvantagem de sobrevalorizar os locais com pequenos números de empresas, estando muito sujeito à variação dos pequenos números. A título de exemplo, um pequeno município com quatro empresas e, eventualmente, uma de serviços avançados, se encontrará muito acima da média nacional, porém não possuirá uma aglomeração produtiva. Simultaneamente, as grandes cidades, com importante diversidade produtiva, são relativamente desvalorizadas, pois o setor em questão terá um peso menor dentro da grande massa de empresas locais.

Portanto, torna-se necessário ponderar o peso do QL com outros índices. O segundo passo é estabelecer o índice denominado de Hirschman-Herfindahl modificado, que compara o peso do setor de serviços avançados nas cidades com o peso de cada cidade no total na estrutura produtiva do País:

\footnotetext{
4 A informação sobre a atividade econômica exercida pelas unidades locais presentes no CEMPRE tem como base a Classificação Nacional de Atividades Econômicas - CNAE 2.0. Este padrão é utilizado no Sistema Estatístico Nacional e na administração pública, sendo o IBGE o órgão responsável por sua manutenção e gestão.
} 


$$
H H m=\left(\frac{E_{j}^{s a}}{E_{B R}^{s a}}\right)-\left(\frac{E_{j}}{E_{B R}}\right)
$$

O terceiro indicador é a simples porcentagem de empresas de serviços avançados de cada município no total de empresas de serviços avançados do País, ou participação relativa (PR).

$$
P R=E_{j}^{s a} \div E_{B R}^{s a}
$$

Para se obter o ICn de cada cidade, soma-se os três indicadores anteriores:

$$
I C n_{j}=\theta_{1} Q L_{j}+\theta_{2} H H m_{j}+\theta_{3} P R_{j}
$$

Cada indicador possui um peso $(\theta)$ que é dado pela variância da dispersão total da nuvem de pontos, obtida pela aplicação de uma técnica multivariada de análise de dados, nomeadamente a análise dos componentes principais dos três indicadores. A partir do software estatístico SAS/STAT, da empresa norte-americana Statistical Analysis System - SAS, são utilizados os valores intermediários obtidos a partir dos autovalores e autovetores e não os valores dos componentes principais em si desta análise multivariada ${ }^{5}$.

Uma vez de posse dos indicadores de concentração normalizados, um filtro foi aplicado nos resultados de maneira a só considerar os municípios e Áreas de Concentração de População relevantes economicamente, que possuem uma escala que justifique a presença de uma aglomeração produtiva, evitando resultados idiossincráticos. Como é impossível falar em aglomerações produtivas sem um número mínimo de empresas, aplicou-se um filtro nos resultado de maneira a excluir os municípios muito pequenos. Com o auxílio do algoritmo de Jenks, que agrupa os dados de valor semelhante o mais possível, categorizou-se a distribuição do número absoluto de empresas em seis classes, sendo excluída a inferior, isto é, os municípios ou Áreas de Concentração de População com menos de 9521 empresas.

Especialmente quanto ao trato das relações multilocalizadas (sede e filial situadas em municípios distintos), empregou-se uma tipologia classificatória que distingue a existência ou não da estrutura de rede, baseada na proposta de Rabino e Occelli (1997). Com a identificação positiva de padrões de rede pelo método do fluxo dominante, estabeleceu-se, em sequência, os níveis hierárquicos dos municípios que constituem os nós. Em seguida, selecionou-se os fluxos dominantes no sentido do município da unidade auxiliar (filial) para o município que abriga a sua respectiva unidade central (sede). Caso a localidade participante da ligação pertença a uma Área de Concentração de População, considerou-se, para efeito de tabulação, evidenciar a ACP, na qual o município está circunscrito.

Uma ligação entre uma filial localizada em Niterói (RJ) e sua sede em Camaçari (BA) foi computada, por exemplo, como sendo entre a ACP do Rio de Janeiro (RJ) e a ACP de Salvador (BA). Além disso, agregaram-se as ligações, resumindo os dados agrupados pelo somatório das empresas envolvidas em cada par de localidades. Finalmente, para a espacialização do tema, considerou-se o décimo superior da distribuição em ordem decrescente do total de empresas compreendido em cada fluxo.

\footnotetext{
5 Para informações detalhadas sobre essa metodologia, consultar a publicação: CROCCO, M. A. et al. Metodologia de identificação de aglomerações produtivas locais. Nova Economia, Belo Horizonte: Universidade Federal de Minas Gerais - UFMG, Faculdade de Ciências Econômicas - FACE, v. 16, n. 2, p. 211-241, maio/jun. 2006. Disponível em: <http://www.scielo.br/scielo. php?script=sci_arttext\&pid=S0103-63512006000200001\&lng=pt\&nrm=iso\&tlng=pt>. Acesso em: out. 2015.
} 
Nos mapeamentos desenvolvidos neste estudo, quando aplicável, de forma a melhor adequar a classificação da variável em evidência, empregou-se o método analítico de otimização de Jenks que identifica as quebras entre classes. O algoritmo utiliza fórmula estatística que consiste basicamente na minimização da soma de variância dentro de cada grupo. Em sequência, procedeu-se a ajustes manuais para melhor acomodação dos valores às faixas de classificação.

Por último, ainda em se tratando da espacialização do tema, estabeleceu-se no Mapa 1 o corte do número abaixo de 500 estabelecimentos-sede de serviços avançados, objetivando destacar os centros de maior relevância.

\section{A geografia das aglomerações produtivas de serviços avançados de apoio às empresas no Brasil}

A localização dos serviços avançados de apoio às empresas - denominadas doravante como empresas de serviços avançados - em termos absolutos pouco se diferencia da distribuição das empresas em geral no Brasil. A falta de um padrão específico à primeira vista deixa evidenciada, assim, que a configuração espacial daquelas empresas reproduzem os processos de concentração econômica na Região Sudeste e, particularmente, no Estado de São Paulo.

Com efeito, ao se realizar uma análise bivariada dos dados, tomando como variável independente o número total de empresas nos municípios e, como variável dependente, a quantidade de empresas de serviços avançados, obtém-se um $\mathrm{R}^{2}$ de 0,98 , isto é, uma correlatividade muito alta das duas variáveis, como evidência por se tratar, em realidade, de um mesmo fenômeno.

Esta situação é um indicativo de que as atividades que compõem os serviços avançados estão bem-inseridas na estrutura produtiva do País, correspondendo aos processos sociais que levam à concentração histórica nas áreas do Centro-Sul. A relativa escassez de infraestrutura logística e de mão de obra qualificada faz com que o leque de localizações possíveis a este tipo de atividade seja restrita, de maneira parecida a outros ramos de negócios, contribuindo para a semelhança encontrada nos padrões gerais de distribuição espacial.

Como o período histórico contemporâneo é marcado pela formação de aglomerações produtivas, especialmente naqueles setores da economia marcados pelo forte componente informacional e de conhecimento nos processos produtivos e na natureza dos produtos, muitas vezes intangível, como é o caso dos serviços avançados, faz-se necessário verificar os pontos no Território Nacional onde se formam concentrações desse tipo de atividade.

Assim, para se obter uma medida mais apurada da configuração espacial das empresas de serviços avançados, aplicou-se o Índice de Concentração normalizado (ICn), que se caracteriza como uma técnica relevante para a identificação de aglomerações produtivas desses serviços em virtude da extrema semelhança entre a localização absoluta dos dados e as das firmas em geral. O ranking de cidades segundo o ICn é exibido na Tabela 1, na qual 41 cidades, dentre as de maior relevância econômica, qualificam-se como possuindo uma concentração significativa de firmas deste setor. 
Como esperado, é notável a hegemonia da Cidade de São Paulo (SP), seguida pela do Rio de Janeiro (RJ), no contexto do País, que condiz com a presença em números absolutos deste tipo de empresa nessas duas metrópoles. A Região Sul também se destaca tendo cinco cidades entre as 10 maiores aglomerações produtivas concentradoras de serviços avançados: Porto Alegre (RS), Blumenau (SC), Curitiba (PR), Florianópolis (SC) e Joinville (SC). Isto é, a região possui três de suas capitais entre as principais cidades caracterizadas como aglomerações de serviços avançados.

Tabela 1 - Principais aglomerações produtivas de serviços avançados, com indicação da posição ocupada, em ordem decrescente do Índice de Concentração normalizado - ICn, segundo as Unidades da Federação

\begin{tabular}{|c|c|c|c|c|c|c|c|}
\hline $\begin{array}{c}\text { Posi- } \\
\text { ção } \\
\text { ocu- } \\
\text { pada }\end{array}$ & $\begin{array}{c}\text { Unidades } \\
\text { da } \\
\text { Federação }\end{array}$ & $\begin{array}{l}\text { Principais aglome- } \\
\text { rações produtivas } \\
\text { de } \\
\text { serviços avançados }\end{array}$ & Icn & $\begin{array}{c}\text { Posi- } \\
\text { ção } \\
\text { ocu- } \\
\text { pada }\end{array}$ & $\begin{array}{c}\text { Unidades } \\
\text { da } \\
\text { Federação }\end{array}$ & $\begin{array}{l}\text { Principais aglome- } \\
\text { rações produtivas } \\
\text { de } \\
\text { serviços avançados }\end{array}$ & Icn \\
\hline & São Paulo & São Paulo & 1,20 & 22 & Paraná & Londrina & 0,47 \\
\hline & Rio de Janeiro & Rio de Janeiro & 0,83 & 23 & São Paulo & Sorocaba & 0,47 \\
\hline 3 & Rio Grande do Sul & Porto Alegre & 0,76 & 24 & Rio Grande do Sul & Caxias do Sul & 0,46 \\
\hline 4 & Santa Catarina & Blumenau & 0,74 & 25 & Goiás & Goiânia & 0,46 \\
\hline 5 & Paraná & Curitiba & 0,72 & 26 & Amazonas & Manaus & 0,45 \\
\hline 6 & Minas Gerais & Belo Horizonte & 0,71 & 27 & Paráraná & Maringá & 0,44 \\
\hline 7 & Distrito Federal & Brasília & 0,66 & 28 & Sergipe & Aracaju & 0,42 \\
\hline 8 & Santa Catarina & Florianópolis & 0,64 & 29 & Ceará & Fortaleza & 0,42 \\
\hline 9 & Santa Catarina & Joinville & 0,62 & 30 & São Paulo & Piracicaba & 0,42 \\
\hline 10 & São Paulo & Campinas & 0,60 & 31 & São Paulo & São José do Rio Preto & 0,42 \\
\hline 11 & São Paulo & Jundiaí & 0,57 & 32 & Rio Grande do Norte & Natal & 0,41 \\
\hline 12 & Minas Gerais & Uberlândia & 0,56 & 33 & Pará & Belém & 0,41 \\
\hline 13 & São Paulo & São José dos Campos & 0,55 & 34 & Alagoas & Maceió & 0,40 \\
\hline 14 & Rio Grande do Sul & Novo Hamburgo & 0,55 & 35 & Paraíba & João Pessoa & 0,38 \\
\hline 15 & Bahia & Salvador & 0,54 & 36 & Minas Gerais & Juiz de Fora & 0,38 \\
\hline 16 & Espírito Santos & Vitória & 0,53 & 37 & Maranhão & São Luís & 0,36 \\
\hline 17 & Mato Grosso & Cuiabá & 0,53 & 38 & Piauí & Teresina & 0,31 \\
\hline 18 & Pernambuco & Recife & 0,53 & 39 & Rio Grande do Sul & Pelotas & 0,31 \\
\hline 19 & Mato Grosso do Sul & Campo Grande & 0,51 & 40 & São Paulo & Franca & 0,27 \\
\hline 20 & São Paulo & Santos & 0,48 & 41 & Bahia & Feira de Santana & 0,23 \\
\hline 21 & São Paulo & Ribeirão Preto & 0,48 & & & & \\
\hline
\end{tabular}

Fonte: Estatísticas do cadastro central de empresas 2011. Rio de Janeiro: IBGE, 2013. Disponível em: <http://www.ibge.gov. br/home/estatistica/economia/cadastroempresa/2011/default.shtm>. Acesso em: out. 2015. 
Em nível macrorregional, percebe-se uma hierarquia na qual as Regiões Sudeste e Sul ocupam uma posição de destaque no terço superior e do meio da distribuição de cidades com os maiores ICn, tendo centros urbanos com portes diferenciados. A Região Centro-Oeste apresenta-se apenas com suas capitais em posições mais medianas, enquanto que as Regiões Nordeste e Norte situam-se em grande parte nos menores ICns. É interessante observar que o comportamento espacial dos serviços avançados nessa escala é condizente com o conceito de espaço de fluxos (CASTELLS, 1999), caracterizado pela presença de certos locais altamente conectados às redes produtivas e vastos espaços excluídos.

Nesse sentido, a Região Sudeste, seguida pela Sul, destacam-se como as macrorregiões mais integradas do ponto de vista da inclusão em redes produtivas com serviços avançados. Embora de forma seletiva e desigual, estas atividades estão mais presentes em seus territórios. Já as outras regiões se caracterizam por uma conectividade mais fraca, limitadas, via de regra, a poucos pontos, quase sempre as capitais estaduais.

Observando as cidades individualmente, a correspondência do ICn com a hierarquia urbana é menor. Brasília (DF) se mostra apenas na sétima posição, sugerindo que o papel desta aglomeração urbana é menos relevante na distribuição dos serviços avançados, ao mesmo tempo que Porto Alegre (RS) apresenta uma concentração deste ramo de negócios superior à Curitiba (PR) e Belo Horizonte (MG). Também há cidades médias que se mostram como forte atrativo para o setor, possuindo um ICn maior que diversas capitais, como os casos de Blumenau e Joinville, ambas do Estado de Santa Catarina.

A região difusa da metrópole paulista, com os Municípios de Campinas, Jundiaí, Santos, São José dos Campos e Sorocaba, possui concentração de serviços avançados de maneira consistente com o conceito de cidade-região, uma ampla área, de fronteiras pouco claras, incorporando diversos núcleos urbanos, periurbanos e mesmo áreas fracamente urbanizadas, mas que formam uma área polinucleada, constituindo um complexo de atividades econômicas diversificadas, com alto grau de integração interna (SCOTT et al., 2001).

Levando em conta que as cidades-regiões cada vez mais funcionam como os nós espaciais essenciais da economia global, sendo o ponto de interconexão da economia doméstica com a global, os serviços avançados são o tipo de atividade capaz de realizar as conexões a longa distância que caracteriza o papel das cidades no período contemporâneo, sobretudo nas de maior porte.

A existência maciça de aglomerações produtivas de serviços avançados na ACP de São Paulo e seu entorno constitui em mais um indicador de que essa área constitui um exemplo emblemático dessa nova modalidade urbana no Brasil ${ }^{6}$. Além disso, o fato de São Paulo estar

\footnotetext{
6 Neste sentido, cabe observar que a Cidade-Região de São Paulo apresenta-se igualmente coerente em termos de integração interna quando analisada sob o ponto de vista do deslocamento para trabalho e estudo, a formação de conurbações e o Produto Interno Bruto - PIB dos municípios que a compõem, conforme observado na publicação Arranjos populacionais e concentrações urbanas do Brasil, divulgada pelo IBGE em 2015.
} 
muito acima das outras cidades como local de concentração das empresas de serviços avançados quer dizer, exatamente por ter como clientes outras empresas, de diversas naturezas, que é fundamental estarem onde existam grandes quantidades de atividades econômicas distintas, cadeias produtivas, polos de atração de força de trabalho, fluxos monetários, pontos de operações de transações internacionais etc., formando redes em diferentes escalas e que atravessam as fronteiras nacionais.

Nesse contexto, pode-se afirmar que os serviços avançados constituem o tipo de atividade que se nutre desse complexo ambiente econômico globalizado contemporâneo, ao mesmo tempo em que contribuem para reproduzi-lo.

\section{A rede de empresas de serviços avançados no Brasil}

No Brasil, foram identificadas 323508 empresas de serviços avançados em 2011 (ESTATÍSTICAS..., 2013). Essas firmas estão representadas por 361418 unidades locais, correspondendo a $7,0 \%$ do total de estabelecimentos dedicados a todo o tipo de atividade econômica. Quanto às conexões entre os endereços de uma mesma empresa, 91,0\% dizem respeito a ligações intramunicipais (locais). Nesta contagem, também fazem parte os registros oriundos de empresas de unidade local única (sem filial). Em termos da quantidade de unidades locais, 98,3\% das empresas contam com um único endereço para o desenvolvimento das suas atividades.

Valendo-se de outra perspectiva de análise, observa-se que pouco menos da metade das empresas de serviços avançados (49,1\%) estão sediadas nos municípios-núcleo das metrópoles, conforme conceituados na pesquisa Regiões de Influência das Cidades - REGIc 2007 (REGIÕES..., 2008). O resultado é consistente com outros estudos sobre a estruturação das aglomerações urbano-metropolitanas, deixando clara a supremacia do nível metropolitano na oferta de serviços deste gênero, com ênfase na concentração de vantagens competitivas de centralidade, em conjunto com empresas parceiras e firmas especializadas em um ambiente de concentração de competências, tanto informacionais quanto de infraestrutura (ANÁLISE..., 2004; GESTÃO..., 2014).

Quando se compara a estrutura das ligações de sedes e filiais das empresas de serviços avançados com a hierarquia urbana (REGIÕES..., 2008), é possível observar que 23,0\% do total dessas empresas corresponde ao nível local, isto é, às unidades sem filiais ou com filial e sede no mesmo município. Esta primeira categorização está concentrada na Grande Metrópole Nacional, topo da hierarquia, atribuída à ACP de São Paulo, maior conjunto urbano do País, contando com 83094 estabelecimentos de serviços avançados (Tabela 2). 
Tabela 2 - Dez principais tipos de ligação entre filiais e seus estabelecimentos-sede de serviços avançados de apoio às empresas, segundo a hierarquia dos centros urbanos e as unidades locais envolvidas - 2011

\begin{tabular}{rlr}
\hline \multicolumn{1}{c|}{ Tipo de ligação (1)/cidade da filial -> cidade da sede (2) } & \multicolumn{1}{c}{$\begin{array}{c}\text { Percentual de } \\
\text { unidades locais (\%) }\end{array}$} \\
\hline 1 & Âmbito local/filial e sede alocadas na Grande Metrópole Nacional (São Paulo/SP) & 23 \\
2 & Âmbito local/(sem classificação hierárquica identificada) & 16,3 \\
3 & Âmbito local/Capital Regional -> Capital Regional & 14,3 \\
4 & Âmbito local/Metrópole -> Metrópole & 13,2 \\
5 & Âmbito local/Metrópole Nacional -> Metrópole Nacional & 8,4 \\
6 & Âmbito local/Centro Local -> Centro Local & 5,6 \\
7 & Âmbito local/Centro Sub-Regional -> Centro Sub-Regional & 4,9 \\
8 & Âmbito local/Centro de Zona -> Centro de Zona & 4,5 \\
9 & Multilocalizada/Centro Local -> Metrópole Nacional & 0,7 \\
10 & Multilocalizada/Capital Regional -> Grande Metrópole Nacional & 0,6 \\
\hline
\end{tabular}

Fontes: 1. Estatísticas do cadastro central de empresas 2011. Rio de Janeiro: IBGE, 2013. Disponível em: <http://www.ibge.gov. br/home/estatistica/economia/cadastroempresa/2011/default.shtm>. Acesso em: out. 2015. 2. Regiões de influência das cidades 2007. Rio de Janeiro: IBGE, 2008. Disponível em: <https://www.ibge.gov.br/home/geociencias/geografia/regic.shtm>. Acesso em: out. 2015.

(1) As ligações em Âmbito local também contemplam empresas contando com unidade local única (sem filial). Ligações multilocalizadas fazem referência à localização de cada filial e de sua respectiva unidade gestora, ambas situadas em municípios distintos. (2) O fluxo cidade da filial -> cidade da sede diz respeito à ligação da filial para com sua matriz, quando aplicável, segundo a classificação hierárquica dos centros urbanos segundo a pesquisa Regiões de Influência das Cidades - REGIC 2007, nos quais os estabelecimentos estão localizados.

Em segundo lugar, também em nível local, 16,3\% couberam às ligações sem classificação hierárquica identificada, em virtude de o município se situar dentro de uma Área de Concentração de População ou de ter sido criado após 2007, ano de referência do estudo REGIC (REGIÕES..., 2008). Na sua maioria, são localidades pertencentes à Região Sudeste e em termos das Unidades da Federação, 65,5\% delas situadas no Estado de São Paulo. Com efeito, muitos destes municípios estão no bojo das grandes aglomerações metropolitanas, com uma média de 205,4 unidades locais computadas para cada centro urbano.

A terceira posição remete aos limites das Capitais Regionais (14,3\%), sinalizando vigor além da concentração nas metrópoles. Deste modo, as ligações internas nos centros classificados como Capitais Regionais superam as conexões também locais envolvendo metrópoles, com exceção da ACP de São Paulo (SP). Os 10,0\% desta categoria com maior número de estabelecimentos envolvidos nas ligações entre sedes e filiais se atém a municípios do Centro-Sul. A propósito, Campinas (SP) lidera o grupamento com 8,4\% das unidades de empresas de serviços avançados (4 365 endereços).

No tipo de ligação 4, isto é, o das ligações locais em metrópoles (Tabela 2) com 13,2\% das unidades locais, sobressaem Belo Horizonte (MG) com 11031 unidades produtivas, seguida de Curitiba (PR), com 10422 unidades e Porto Alegre (RS) com 10 011. No quinto lugar (8,4\%), têm-se as ligações locais envolvendo Rio de Janeiro (RJ) e Brasília (DF) - Metrópoles Nacionais, sendo que a metrópole fluminense centraliza 72,6\% dos endereços, considerando a classe isolada. 
Outras categorizações em âmbito local se sucedem dos tipos de ligação 6 a 8. Interrompendo este padrão, surge no tipo 9, que reúne $0,7 \%$ das unidades locais, ligações multilocalizadas oriundas das filiais situadas em centros locais se reportando a estabelecimentos-sede localizadas nas Metrópoles Nacionais. A grande capilaridade de empresas, como o Banco do Brasil, vinculadas a Brasília (DF), por exemplo, justifica o maior valor absoluto nesta categoria (932 firmas). Encerrando a tabela, com o percentual de 0,6\%, verifica-se a comunicação das filiais em Capitais Regionais com a Metrópole de São Paulo (SP). Cabe observar que 40,6\% destas sucursais pertencem ao mesmo estado da Grande Metrópole Nacional.

Comparando o quantitativo de empresas com outros recortes espaciais, constata-se em termos das Grandes Regiões um predomínio da Região Sudeste sobre o restante do País, concentrando 65,8\% das empresas, vindo em seguida a Região Sul com 17,7\%. A Região Nordeste fica na terceira colocação, atingindo $8,4 \%$, enquanto em quarto e quinto lugares vêm as Regiões Centro-Oeste e Norte, reunindo, respectivamente, 6,2\% e 1,9\% das empresas.

Com base nas Unidades da Federação, São Paulo exibiu as maiores participações relativas, contando com o percentual de $46,3 \%$ de todas as empresas de serviços avançados, enquanto o Rio de Janeiro chegou ao segundo lugar com 9,9\% e Minas Gerais, em terceiro, obteve o percentual de $8,1 \%$.

Em outra escala, isto é, no nível de Área de Concentração de População (REGIÕES..., 2008), a ACP de São Paulo, que abrange o Município de São Paulo e os municípios vizinhos de Barueri, Guarulhos, Osasco, São Caetano do Sul, dentre outros, a participação relativa das empresas de serviços avançados no total nacional alcança 35,0\%, reforçando seu alto grau de concentração geográfica no Território Nacional, reafirmando o conceito de cidade-região.

Quanto ao Município de São Paulo, sua centralidade é manifesta em termos quantitativos pela maior participação relativa no total dos municípios brasileiros. Apenas dentro do município se encontram 25,2\% das empresas de serviços avançados, 81453 em valores absolutos. Neste sentido, a capital paulista figura na primeira classificação do Mapa 1. O Município do Rio de Janeiro, com 21827 empresas, aparece na segunda classificação. No terceiro nível têm-se oito municípios, todos do Centro-Sul. Cinco deles são metrópoles: Belo Horizonte (MG), 10912 empresas; Curitiba (PR), 10338 empresas; Porto Alegre (RS), 9829 empresas; Brasília (DF), 8027 empresas e Salvador (BA), 3935 empresas. Os municípios que não são centros metropolitanos pertencem ao Estado de São Paulo e às ACPs desta Unidade da Federação: Santana do Parnaíba (6 052 empresas); Poá (4 523 empresas) e Campinas (4 359 empresas).

As ligações entre filiais e respectivas sedes, estabelecidas em municípios não coincidentes, estão representadas também no Mapa 1. Desta forma, os fluxos exibidos simbolizam a atuação das empresas de serviços avançados em mais de um endereço. Em se tratando do percentual de 10,0\% das maiores interações, constata-se que quase todos os registros se manifestam na forma de ligações hierárquicas ascendentes diretas, ou seja, convergindo das unidades auxiliares alocadas nos centros menores para os centros hierarquicamente superiores na rede urbana, onde se encontram seus estabelecimentos-matriz. 
Nesse contexto, o fluxo mais intenso, em relação ao total de empresas envolvidas, parte da ACP do Rio de Janeiro para a ACP de São Paulo. A única exceção ao padrão hierárquico ascendente se encontra no segundo maior fluxo, inverso do primeiro. Este último contém filiais alocadas na ACP de São Paulo que convergem para suas matrizes na ACP do Rio de Janeiro, sendo classificado como hierárquico descendente direto.

Além disso, consolidando a condição de centro polarizador de São Paulo (SP), constata-se que $77,5 \%$ do total de ligações dos fluxos dominantes no País se dirigem para a capital paulista. Por sua vez, 41,2\% dos centros que abrigam estabelecimentos-sede são os municípios-núcleo pertencentes às Metrópoles de Porto Alegre (RS), Belém (PA), Curitiba (PR), Rio de Janeiro (RJ), Brasília (DF) e Belo Horizonte (MG).

No que concerne ao raio de ação das ligações do Mapa 1, a média da distância dos fluxos que convergem para São Paulo (SP) é a segunda maior (935,2 km), superando à média geral $(784,1 \mathrm{~km})$. Este valor se coaduna com os resultados apresentados no parágrafo anterior, denotando a comunicabilidade da Grande Metrópole Nacional com centros distribuídos por todo o Território Nacional nas diversas hierarquias constantes da REGIC 2007 (REGIÕES..., 2008). As maiores distâncias estão atreladas aos pares formados com Brasília (DF) que alcançam 1 034,7 km em média. A localização estratégica da Capital Federal no interior do Território Nacional gerindo filiais situadas notadamente na Região Nordeste e na região do Triângulo Mineiro, explica, em grande parte, sua posição de destaque.

Em contraposição à geografia dos centros de gestão de serviços avançados que segue, grosso modo, distribuição demográfica e econômica do País, observam-se os municípios que não apresentamm sedes (unidades centrais) de serviços avançados alocadas em seus limites. Conforme o Mapa 2, a localização de tais municípios não permite a identificação de um padrão espacial que possa ser representativo em escala nacional.

Contudo, em nível regional, algumas observações podem ser feitas. Assim, se por um lado na franja litorânea da região sul do Estado da Bahia até a região do sudeste catarinense, praticamente todos os municípios possuam empresas do gênero, por outro lado, na parte setentrional do Estado do Amazonas, no centro-oeste paraense e, em inúmeras áreas dos Estados do Acre, Roraima, Amapá, Piauí, Rio Grande do Norte, Paraíba, Alagoas e Tocantins, grandes vazios são observados quanto à ocorrência de municípios com a presença de serviços avançados. Finalmente, pode-se observar que, de forma mais fragmentada, porém quantitativamente significante, são observadas áreas desconectadas nas demais Unidades da Federação. 


\section{Mapa 1 - Total de empresas de serviços avançados de apoio às empresas por município e principais ligações multilocalizadas entre filiais e sedes - 2011}

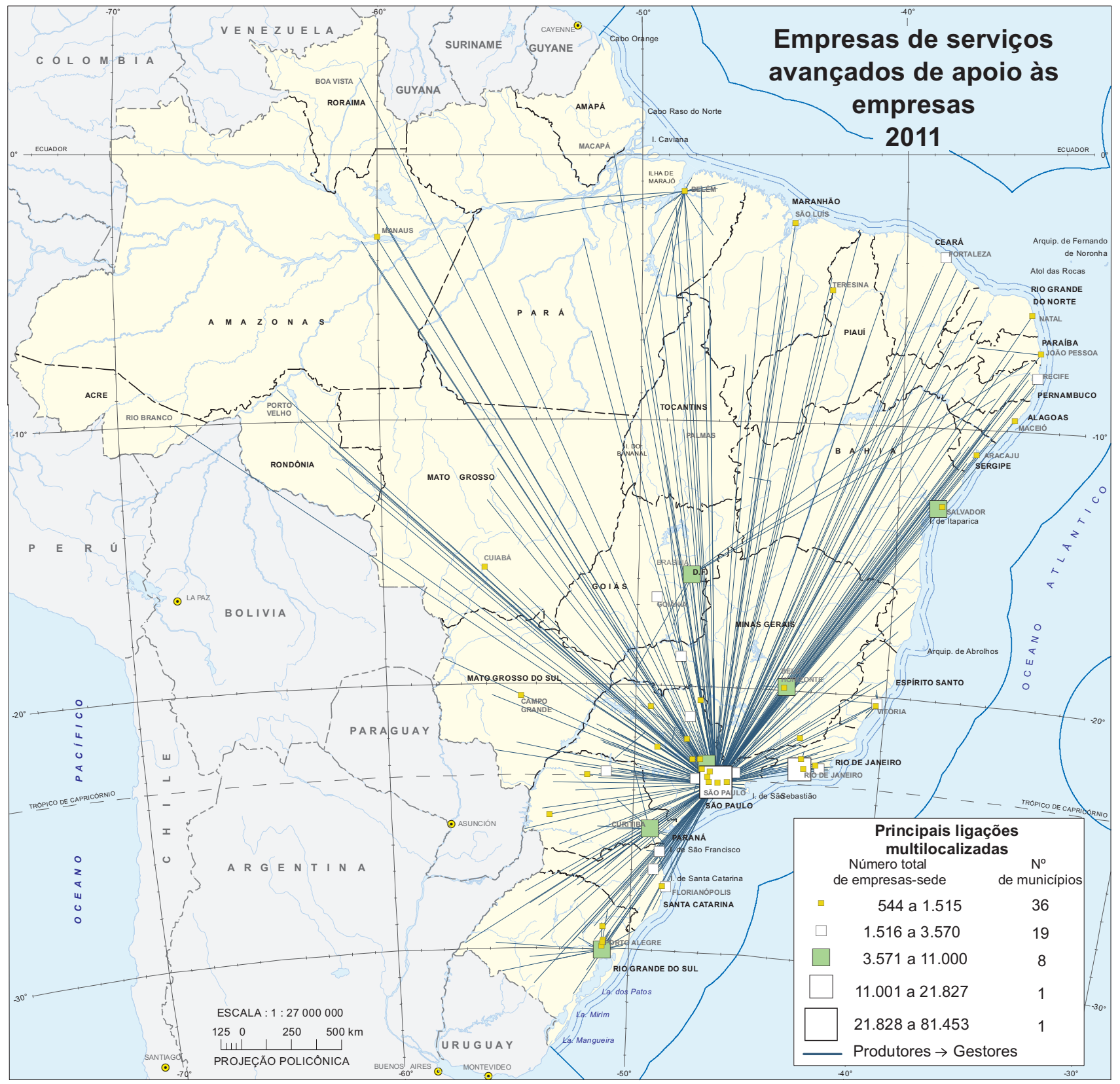

Fontes: 1. Estatísticas do cadastro central de empresas 2011. Rio de Janeiro: IBGE, 2013. Disponível em: <http://www.ibge.gov.br/home/estatistica/ economia/cadastroempresa/2011/default.shtm>. Acesso em: out. 2015. 2. Classificação nacional de atividades econômicas - CNAE: versão 2.0. Rio de Janeiro: IBGE, 2007. Disponível em: <http://concla.ibge.gov.br/classificacoes/por-tema/>. Acesso em: out. 2015.

Notas: 1. No tocante ao "número total de empresas-sede", foram considerados somente os municípios que abrigam um número superior a 500 estabelecimentos-sedes de serviços avançados de apoio às empresas em sua localidade.

2. Nas "principais ligações multilocalizadas", no sentido das unidades produtoras de cada empresa (filiais) para suas matrizes, situadas em outro município, foram espacializados somente os fluxos de pares de municípios contemplando o décimo superior da distribuição, em ordem decrescente da quantidade de empresas associadas a cada par. 
Mapa 2 - Municípios sem matrizes de serviços avançados - 2011

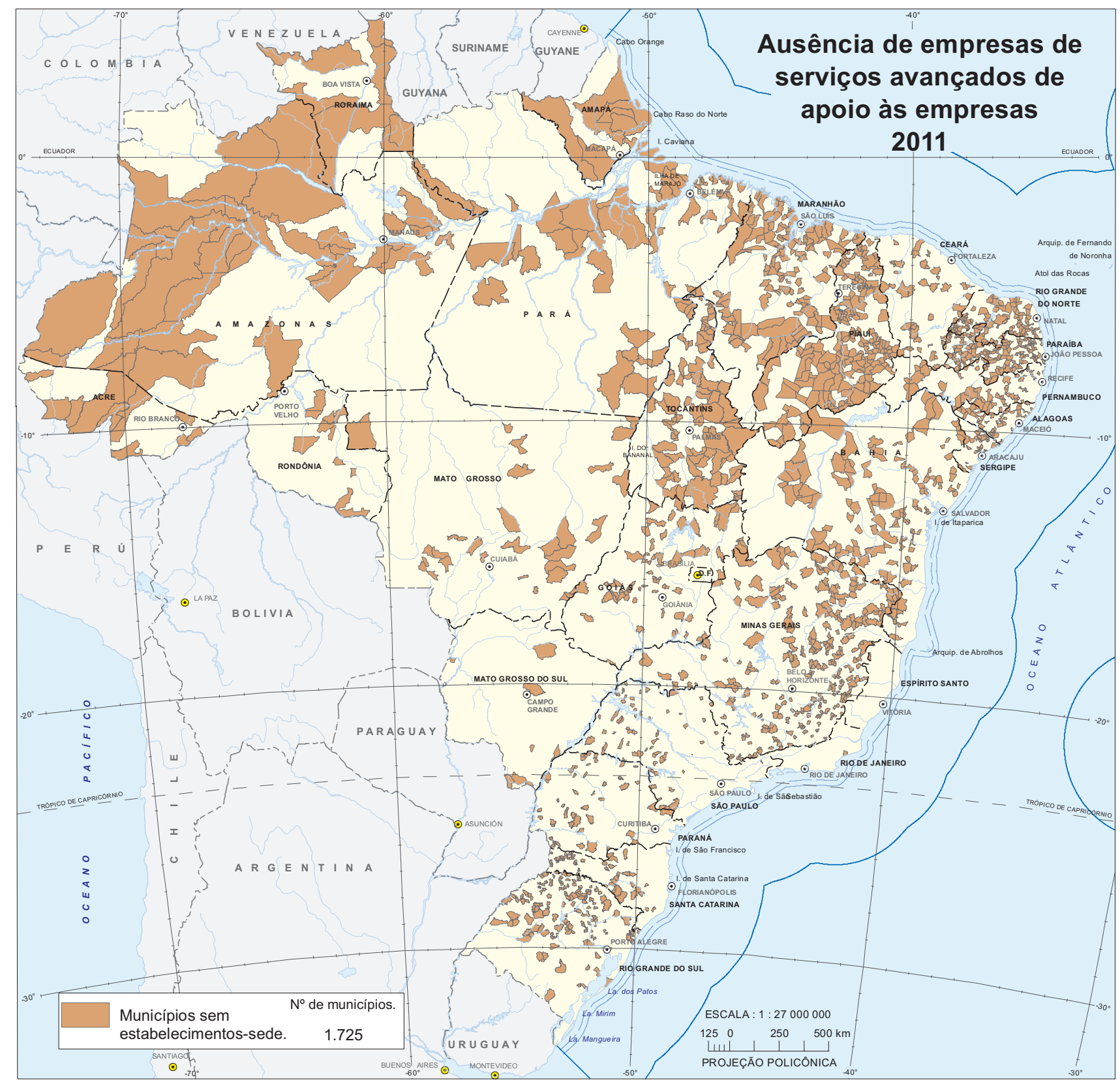

Fontes: 1. Estatísticas do cadastro central de empresas 2011. Rio de Janeiro: IBGE, 2013. Disponível em: <http://www.ibge.gov.br/home/estatistica/ economia/cadastroempresa/2011/default.shtm>. Acesso em: out. 2015. 2. Classificação nacional de atividades econômicas - CNAE: versão 2.0. Rio de Janeiro: IBGE, 2007. Disponível em: <http://concla.ibge.gov.br/classificacoes/por-tema/>. Acesso em: out. 2015. 


\section{Considerações finais}

Os indicativos deste estudo confirmam o quadro delineado na publicação Gestão do território 2014, onde as Metrópoles de São Paulo (SP) e Rio de Janeiro (RJ) chamam atenção ao oferecer quase todo o leque de variedades de serviços avançados de apoio às empresas, seguidos, em um segundo grupo, pelas demais metrópoles.

A pesquisa atual, de maneira análoga, permite observar que os municípios-núcleo das metrópoles brasileiras apresentam o maior quantitativo de empresas de serviços avançados. A pesquisa serviu, em particular, para reafirmar a percepção da centralidade inerente à capital paulista, seja tomando o Município de São Paulo isoladamente, seja fazendo sua análise articulada à metrópole. A hegemonia da capital paulista é ademais indicada pela própria desproporção verificada entre os índices de concentração de serviços avançados nessa cidade em relação às demais. Este motor de polarização também adensa o seu entorno, sobrepondo em números o Estado de São Paulo perante as demais Unidades da Federação.

Além disso, do ponto de vista sugerido por Hanssens e Derudder (2011), que observa as cidades belgas sob o binômio cidades que produzem versus cidades que consomem serviços avançados empresariais, pode-se traçar um paralelo no presente estudo.

Nesse sentido, apesar de não haver pretensão em replicar a metodologia dos autores e verificar a relação produção-consumo, como a maior parte dos endereços dos estabelecimentos-sede e de suas filiais está no mesmo município (91,0\%), a proporção sugere que o emprego do serviço avançado ocorre majoritariamente na mesma localidade da sua elaboração, reforçando a ideia de polos de produção e de preferência pela cidade-região brasileira, nomeadamente São Paulo. Diante do fato, importa dizer que as condições de operação das empresas de serviços avançados, no caso brasileiro, se encontram espacialmente limitadas e concentradas.

Entretanto, a existência de aglomerações secundárias, como no eixo Curitiba (PR), Blumenau (SC), Joinville (SC) e Florianópolis (SC), com índices de aglomeração semelhantes ou mesmo superiores a algumas metrópoles, mostra uma situação mais complexa do que previsto pela teoria clássica das localidades centrais, sugerindo o peso das instituições locais em atrair serviços avançados e uma maior importância do city-ness nesses centros urbanos.

Além dessa zona secundária de concentração de serviços avançados, a apreciação das ligações dominantes entre sedes e filiais, também ajuda a perceber importantes especificidades locais, como é o caso do peso de Belém em comandar diversas cidades no Estado do Pará; Porto Alegre em relação ao Estado do Rio Grande do Sul, estado tradicionalmente centralizado em sua capital; e Brasília (DF), com uma relação mais forte com alguns municípios na Região Nordeste. Entretanto, deve-se chamar a atenção que as ligações das firmas multilocalizadas, isto é, cujas espacialidades traduzem estratégias intrafirma, fazem-se esmagadoramente com São Paulo, o que é consistente com a grande presença de empresas e de comando desta Grande Metrópole Nacional.

A maciça concentração na Metrópole de São Paulo e o fato de as sedes aí localizadas possuírem um alcance espacial que praticamente incorpora todo o Território Nacional, torna plausível, de acordo com Rossi, Beaverstock e Taylor (2007) e Tolosa (2005) que essa aglomeração urbana constitua um gateway, isto é, um ponto de interconexão do Brasil com a economia mundial, se constituindo assim em uma cidade global. 
Embora a interconexão entre as cidades brasileiras não seja, em geral, negligenciável, no que tange os serviços avançados de apoio às empresas, o papel central dessa metrópole é único e as informações estatísticas, analisadas à luz da teoria dos fluxos centrais, reforçam o papel de São Paulo como um relé entre os níveis nacional e internacional.

Nesse sentido, verifica-se que $34,6 \%$ das 1000 maiores corporações identificadas pelo periódico Valor Econômico estão situadas nos Municípios de São Paulo (SP) e Rio de Janeiro (RJ) (RANKING..., 2012). Ademais, 52,8\% são empresas atuando em metrópoles. Esses percentuais elevados no âmbito metropolitano se coadunam com os resultados até aqui verificados quanto aos serviços empresariais. Portanto, recapitulando a argumentação de Hertog (2000) quanto à sinergia entre as empresas de serviços avançados de apoio às empresas e sua clientela, reforça-se o entendimento de que estes serviços intensivos em conhecimento se prestam tanto como facilitadores, quanto como carreadores, ou mesmo como fonte primária de práticas de inovação. Deste modo, a dinâmica promovida no cerne do terciário avançado propaga conhecimento e insumos, incorporando setores de ponta envolvidos no processo.

Resumindo, os padrões espaciais ligados às empresas de serviços avançados possuem um caráter metropolitano, mostrando que suas condições de operação parecem estar profundamente conectadas com as economias urbanas.

A elevadíssima concentração no Município de São Paulo, em patamares bem superiores aos demais núcleos urbanos do País, indica que os serviços avançados não podem fugir do círculo que reúne as empresas que são seus clientes e da concentração de serviços, mão de obra qualificada, know-how, bem como das redes sociais que compõem um complexo de empresários e força de trabalho especializada e qualificada que constroem um conhecimento coletivo sobre esse segmento, fazendo com que este arranjo de competências sistêmicas encontre naquela metrópole seu ponto de funcionamento fundamental.

\section{Referências}

ANÁLISE das regiões metropolitanas do Brasil: relatório da atividade 1: identificação dos espaços metropolitanos e construção de tipologias. Rio de Janeiro: Observatório das Metrópoles, 2004. 93 p. Disponível em: <http://www.observatoriodasmetropoles.ufrj.br/ produtos/produto_mc_1.pdf>. Acesso em: out. 2015.

ARRANJOS populacionais e concentrações urbanas do Brasil. Rio de Janeiro: IBGE, 2015. 167 p. Disponível em: <ftp://geoftp.ibge.gov.br/organizacao_territorial/arranjos_ populacionais/arranjos_populacionais.pdf>. Acesso em: out. 2015.

BROWN, S. Central place theory: sixty years on. In: CONFERENCE ON HISTORICAL RESEARCH IN MARKETING AND MARKETING THOUGHT, 6.,1993, Atlanta. Proceedings... East Lansing: Michigan State University, 1994. p. 69-87. Disponível em: <http://learn. quinnipiac.edu/charm/CHARM\%20proceedings/CHARM\%20article\%20archive $\% 20$ pdf\%20format/Volume\%206\%201993/69\%20brown.pdf>. Acesso em: out. 2015. 
CASTELLO BRANCO, M. L. G. Áreas de concentração de população. 2006. Trabalho apresentado na mesa-redonda "Áreas de concentração de população: regiões metropolitanas, cidades médias, cidades gêmeas, cidades de fronteiras", no II Encontro Nacional de Produtores e Usuários de Informações Sociais, Econômicas e Territoriais, realizado no Rio de Janeiro, 2006.

CASTELLS, M. A sociedade em rede. Tradução de RoneideVenancio Majer com a colaboração de Klauss Brandini Gerhardt. In: A era da informação: economia, sociedade e cultura. São Paulo: Paz e Terra, 1999. v. 1.

CHRISTALLER, W. Central places in southern Germany. Englewood Cliffs: Prentice-Hall, 1966. $230 \mathrm{p}$.

CLASSIFICAÇÃO nacional de atividades econômicas - CNAE: versão 2.0. Rio de Janeiro: IBGE, 2007. 425 p. Acompanha 1 CD-ROM. Disponível em: <http://concla.ibge.gov.br/ classificacoes/por-tema/>. Acesso em: out. 2015.

CROCCO, M. A. et al. Metodologia de identificação de aglomerações produtivas locais. Nova Economia, Belo Horizonte: Universidade Federal de Minas Gerais - UFMG, Faculdade de Ciências Econômicas - FACE, v. 16, n. 2, p. 211-241, maio/jun. 2006. Disponível em: $<$ http://www.scielo.br/scielo.php?script=sci_arttext\&pid=S0103-63512006000200001\&lng $=$ pt\&nrm=iso\&tlng=pt $>$. Acesso em: out. 2015.

ESTATÍSTICAS do cadastro central de empresas 2011. Rio de Janeiro: IBGE, 2013. 193 p. Acompanha 1 CD-ROM. Disponível em: <http://www.ibge.gov.br/home/estatistica/ economia/cadastroempresa/2011/default.shtm>. Acesso em: out. 2015.

GESTÃO do território 2014. Rio de Janeiro: IBGE, 2014. 118 p. Acompanha 1 CD-ROM. Acima do título: Redes e fluxos do território. Disponível em: <http://www.ibge.gov.br/home/ geociencias/geografia/redes_fluxos/gestao_do_territorio_2014/default.shtm?c=11>. Acesso em: out. 2015.

HANSSENS, H.; DERUDDER, B. The urban geography of advanced producer service transaction links in Belgium. Belgeo: revue belge de géographie, Bruxelles: Belgian National Committee for Geography: Société Royale Belge de Géographie - SRBG, n. 1-2, p. 17-28, 2011. Disponível em: <https://belgeo.revues.org/6345>. Acesso em: out. 2015.

HERTOG, P. D. Knowledge-intensive business services as co-producers of innovation. International Journal of Innovation Management, Singapore: World Scientific, v. 4, n. 4, p. 491-528, Dec. 2000.

RABINO, G. A.; OCCELLI, S. Understanding spatial structure from network data: theoretical considerations and applications. Cybergeo: european journal of geography, Marseille: Revues.org, n. 29, June 1997. Disponível em: <http://cybergeo.revues.org/2199?lang=pt>. Acesso em: out. 2015.

RANKING das 100 maiores. In: VALOR ECONÔMICO. Valor 1000. São Paulo, 2012. Disponível em: <http://www.valor.com.br/empresas/2801254/ranking-das-1000-maiores>. Acesso em: fev. 2014. 
REGIÕES de influência das cidades 2007. Rio de Janeiro: IBGE, 2008. 201 p. Acompanha 1 CD-ROM. Disponível em: <http://www.ibge.gov.br/home/geociencias/geografia/regic. shtm>. Acesso em: out. 2015.

ROSSI, E. C.; BEAVERSTOCK, J. V.; TAYLOR, P. J. Transaction links through cities: 'decision cities' in outsourcing by leading Brazilian firms. Geoforum, Amesterdam: Elsevier, v. 38, n. 4, p. 628-642, July 2007. Disponível em: <http://www.sciencedirect.com/science/article/pii/ S0016718506001771? np=y\#>. Acesso em: out. 2015.

SASSEN, S. As cidades na economia mundial. Tradução Carlos Eugênio Marcondes de Moura. São Paulo: Studio Nobel, 1998. 190 p. (Megalópolis).

SCOTT, A. J. Regions and the world economy: the coming shape of global production, competition and political order. Oxford: Oxford University Press, 1998. 177 p.

SCOTT, A. J. et al. Global city-regions. In: SCOTT, A. J. (Ed.). Global city-regions: trends, theory, policy. Cambridge: Oxford University Press, 2001. p. 11-30.

TAYLOR, P. J. History and geography: Braudel's 'extreme longue durée' as generics? In: LEE, R. E. (Ed.). The longue durée and world-system analysis. New York: State University of New York Press, 2012. p. 35-64. Disponível em: <http://www.lboro.ac.uk/gawc/rb/rb284.html>. Acesso em: jan. 2016.

Specification of the word city network. Geographical Analysis, Columbus: Ohio State University Press, Department of Geography; Hoboken: Wiley, v. 33, n. 2, p. 181-194, Apr. 2001. Disponível em: <http://onlinelibrary.wiley.com/doi/10.1111/j.1538-4632.2001. tb00443.x/pdf>. Acesso em: out. 2015.

TAYLOR, P. J.; HOYLER, M.; VERBRUGGEN, R. External urban relational process: introducing central flow theory to complement central place theory. Urban Studies, Thousand Oaks: SAGE, v. 47, n. 13, p. 2803-2818, Nov. 2010. Disponível em: <http://usj.sagepub.com/ content/47/13/2803.short>. Acesso em: jan. 2016.

TOLOSA, H. The Rio/São Paulo extended metropolitan region: a quest for global integration. In: RICHARDSON, H. W.; BAE, C.-H. C. (Ed.). Globalization and urban development. Berlin: Springer, c2005. (Advances in spatial science). p. 125-146. 